\title{
The Impact Of Pelvic Floor Muscle Training On Urinary Incontinence In Men After Radical Prostatectomy (RP) - A Systematic Review
}

This article was published in the following Dove Press journal: Clinical Interventions in Aging

\section{Agnieszka Strączyńska Magdalena Weber-Rajek (D) \\ Katarzyna Strojek (iD) \\ Zuzanna Piekorz \\ Hanna Styczyńska \\ Aleksander Goch \\ Agnieszka Radzimińska}

Department of Physiotherapy, Nicolaus Copernicus University in Torun

Collegium Medicum in Bydgoszcz, Bydgoszcz, Poland
Correspondence: Magdalena Weber-Rajek Department of Physiotherapy, Nicolaus Copernicus University in Torun Collegium Medicum in Bydgoszcz, ul. Jagiellońska 13-15, Bydgoszcz 85-067, Poland Email magdawr69@gmail.com
Purpose: The purpose of this study was to determine the efficacy of pelvic floor muscle training (PFMT) in the treatment of urinary incontinence (UI) in men after radical prostatectomy (RP).

Methods: PubMed, ScienceDirect, and Cochrane Library databases were searched for studies published in years 2000-2019. We included randomized controlled trials in English which compare clinic-based vs home-based PFMT, preoperative and postoperative PFMT, supervised vs unsupervised PFMT, and PFMT alone vs no treatment at all.

Results: Eight articles were included in the final review. There was a total of 1078 patients aged 45-75 in all study groups. The study participants received radical retropubic prostatectomy or radical prostatectomy. Included studies assessed the following interventions: preoperative and postoperative PFMT, supervised vs home-based PFMT, unsupervised PFMT vs no treatment at all, and PFMT combined with resistance and flexibility exercises vs PFMT alone.

Conclusion: PFMT is an effective treatment for urinary incontinence in men after radical prostatectomy. PFMT improves not only physical parameters but also the quality of life of men after RP.

Keywords: pelvic floor muscle training, prostatectomy, urinary incontinence

\section{Introduction}

Prostate cancer ( $\mathrm{PCa})$ is a malignant tumor commonly diagnosed among men in the USA and Europe. ${ }^{1}$ Age is strongly associated with the risk of prostate cancer. PCa is rare in men under 40 , whereas the incidence of prostate cancer is increasing rapidly after the age of 55 years. ${ }^{1}$ Epidemiological data show that in 350 men, only one person under the age of 50 will be diagnosed with prostate cancer, and the incidence increases to 1 in 52 men aged 50 to 59. In contrast, the incidence is almost $60 \%$ in men older than 65 years. ${ }^{2}$ About $81 \%$ of cases of prostate cancer are detected early on, which allows patients to receive effective treatment. The choice of treatment depends on tumor stage and patient age. Although until recently surgical treatment was reserved for patients with prostate cancer limited to the prostate, nowadays criteria for surgical or radiotherapeutic treatment options are broadened with the intent to cure the illness. ${ }^{3}$ Prostatectomy may be performed classically as open surgery or as laparoscopic or robotic-assisted laparoscopic surgery. High-risk cancer patients may undergo radical prostatectomy which includes the removal of the entire prostate gland (in the section between the external sphincter and the bladder neck), 
together with both seminal vesicles, prostatic urethra, and bilateral pelvic lymph nodes. Nevertheless, lymphadenectomy is not necessary for low-risk cancer patients because the risk of lymph node metastasis in these patients is less than $5 \%{ }^{3}$ The surgery provides very good oncological results and allows patients to maintain voluntary urinary continence and sexual function. ${ }^{3}$ Even though RP has been improved over decades, patients are still at risk of surgical and post-surgical complications. The most common complications include urinary incontinence and erectile dysfunction. $^{4}$ Multi-disciplinary treatment approach determined by urologists, physiotherapists, and other healthcare professionals is the treatment standard for urinary incontinence after radical prostatectomy. Pelvic floor muscle training is recognized as the physiotherapeutic modality for the treatment of urinary incontinence in men after radical prostatectomy. This method is recommended by the European Association of Urology. ${ }^{5}$ However, it is still difficult to identify the actual value of PFMT because there are not enough RCTs with large sample sizes. Furthermore, the impact of PFMT on UI treatment in men after RR is yet to be defined, and there is insufficient information on all the benefits of this conservative treatment.

\section{The Purpose Of The Systematic Review}

The purpose of this study was to determine the efficacy of pelvic floor muscle training (PFMT) in the treatment of urinary incontinence (UI) in men prior to and after radical prostatectomy (RP). Randomized controlled trials (RCTs) on the use of PFMT after RP were included in this systematic review.

\section{Methods}

\section{Data Sources}

The present study is a systematic review of controlled clinical trials (RCTs). We identified studies from the following three databases: PubMed, Cochrane Library, and ScienceDirect from years 2000 to 2019.

\section{Study Selection}

The electronic medical databases were searched in May 2019 for studies from years 2000 to 2019. Three independent reviewers (K.S., Z.P., and A.S.) conducted the database searches to avoid missing relevant publications. Each investigator analyzed only RCTs published in English that examined the effect of pelvic floor muscle training on men with urinary incontinence pre- and post-prostatectomy. Identified reports were critically appraised for quality and relevance. Several thousand articles were found using the following search keywords: nonsurgical treatments OR conservative treatment OR conservative management OR pelvic floor muscle training AND prostatectomy OR/AND urinary incontinence. RCTs that compared clinic-based vs home-based PFMT, PFMT prior to vs after the prostatectomy, supervised vs unsupervised PFMT, and PFMT alone vs no treatment at all were included in the systematic review. In addition, the following study exclusion criterion was added: combined therapy (electrostimulation, biofeedback, vibration, magnetic stimulation, and device therapy) and surgery type (robot assisted and TURP) to improve the quality of relevant searches. Only articles that met the following specific criteria were included in the analysis: prostate cancer patients received RP; the experimental or control groups received preoperative and postoperative PFMT or no treatment. Studies which contained insufficient information about the research methodology were excluded.

\section{Data Extraction}

Two reviewers (M.W.R. and A.R.) independently extracted the data to ensure data reliability and accuracy. The following information was extracted from all qualified studies: first author's name, country and year of publication, age of participants, sample size, intervention time, surgery and intervention type, study design, outcome measures, and main results. Moreover, the description of the study design contained details about the duration of observation and patient assessment time points. Any differences in opinion were resolved through discussion.

\section{Quality Assessment}

Systematic review methods were based on the PRISMA checklist (Preferred Reporting Items for Systematic Reviews and Meta-Analyses) to strengthen reporting (Figure 1). ${ }^{6}$

Methodological quality of the selected studies was assessed using the PEDro scale which is commonly employed in systematic review papers (Table 1). The PEDro scale scores 10 items: eligibility, randomization, allocation of subjects, similarity at baseline, subject blinding, therapist blinding, assessor blinding, $>85 \%$ follow-up for at least one key outcome, intention of treatment, statistical comparison between groups, estimated points, and variability measures for at least one key outcome. The final score is calculated by adding up all points. Two evaluators (Z.P. and A.S.) independently classified the data using the PEDro scale. In our systematic review, we included only high-quality studies which scored at least 6 points on the scale. ${ }^{7}$ 


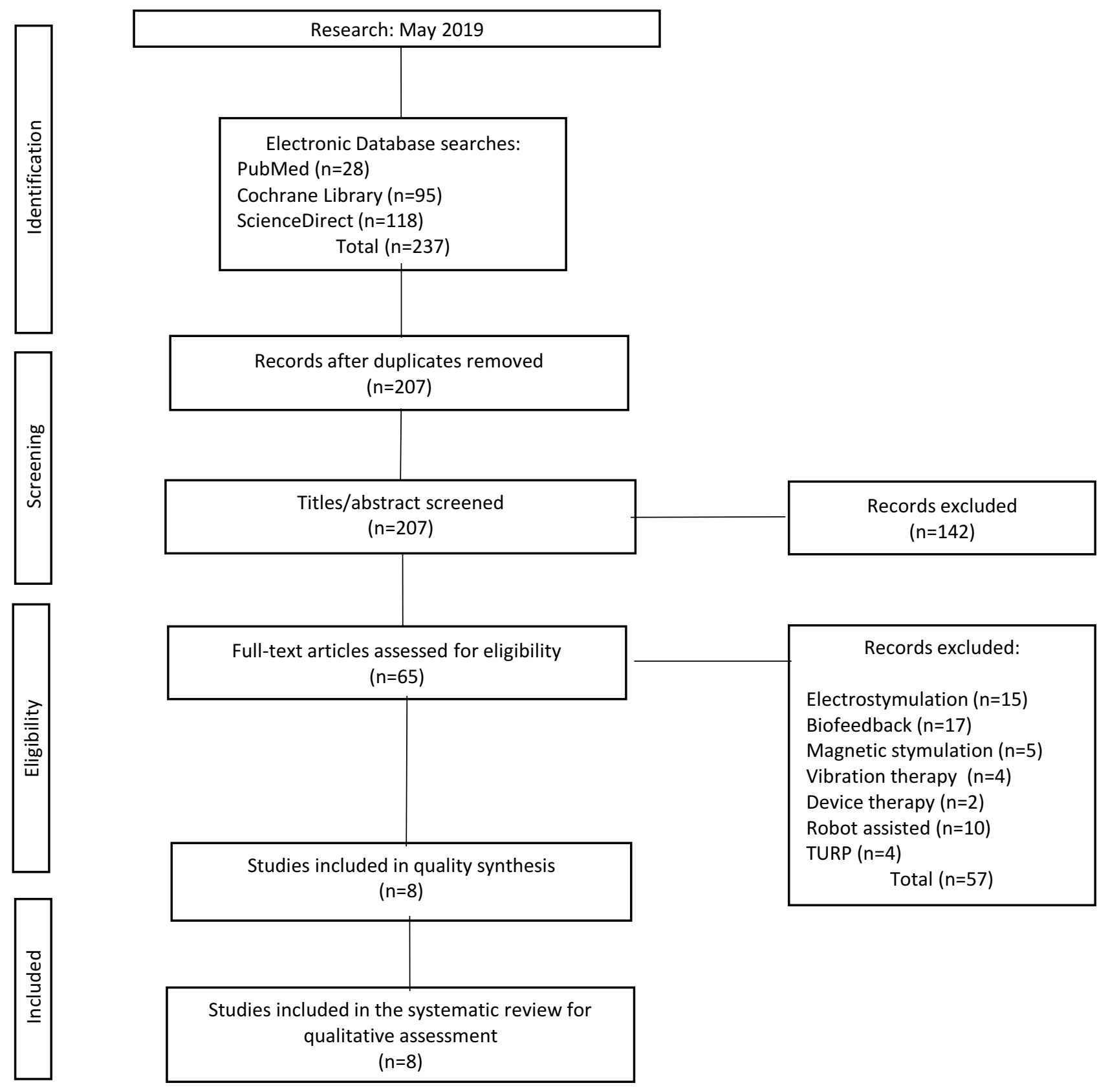

Figure I Flow diagram of the study selection process.

\section{Results And Discussion \\ Record Results}

Consequently, 237 publications were found in 3 databases.

Then, 30 duplicated articles were removed. The three researchers involved in data analysis read 207 abstracts and excluded 142 articles that did not focus on patients with UI following prostatectomy. After prior analysis of the full texts, another 57 articles were excluded based on the exclusion criteria. Ultimately, eight articles were included in this systematic review. According to the methodological quality assessment performed using the PEDro scale, 6 studies were carried out at a high level and only two at a satisfactory level.

\section{Study Characteristics}

The electronic medical databases were searched in May 2019. The studies were selected using a very detailed flowchart (Figure 1). Eight articles were included in the final review (Table 1). There was a total of 1078 patients $(E G=554$, $\mathrm{CG}=524)$ aged $45-75$ in all study groups. In 6 studies, the 
Table I Methodological Quality Of The Included Studies Evaluated With The PEDro Scale

\begin{tabular}{|c|c|c|c|c|c|c|c|c|}
\hline $\begin{array}{l}\text { Study/Criteria Of The PEDro } \\
\text { Scale }\end{array}$ & $\begin{array}{l}\text { Centemero } \\
\mid 2012 /\end{array}$ & $\begin{array}{l}\text { Dubbelman } \\
\mid 2012 /\end{array}$ & $\begin{array}{l}\text { Filocamo } \\
\text { /2005/ }\end{array}$ & $\begin{array}{l}\text { Manassero } \\
\text { /2007/ }\end{array}$ & $\begin{array}{l}\text { Nilssen } \\
\text { /20I2/ }\end{array}$ & $\begin{array}{l}\text { Overgard } \\
/ 2008 /\end{array}$ & $\begin{array}{l}\text { Park } \\
/ 20 I 2 I\end{array}$ & $\begin{array}{l}\text { Patel } \\
\mid 2013 /\end{array}$ \\
\hline Eligibility & + & + & + & + & + & + & + & + \\
\hline Randomization & + & + & $?$ & + & + & + & + & + \\
\hline Allocation of subjects & + & + & $?$ & $?$ & $?$ & $?$ & + & $?$ \\
\hline $\begin{array}{l}\text { Similar groups at baseline in } \\
\text { terms of the most important } \\
\text { prognostic indicators }\end{array}$ & + & + & + & $?$ & + & + & + & + \\
\hline Blinded subjects & - & - & - & - & - & - & + & - \\
\hline Blinded therapist & - & - & - & - & + & + & - & - \\
\hline Blinded evaluators & + & - & - & + & - & - & + & - \\
\hline Adequate follow-up & + & + & + & + & + & + & + & $?$ \\
\hline Intention of treatment & + & + & + & + & + & + & + & + \\
\hline Comparison between groups & + & + & + & + & + & + & + & + \\
\hline Estimated points and variability & + & + & + & + & + & + & + & + \\
\hline Total score & 9 & 8 & 6 & 7 & 8 & 8 & 10 & 6 \\
\hline
\end{tabular}

Notes: +The criteria are clearly satisfactory; -The criteria are clearly not satisfactory; ?The criteria are unclear.

participants received radical retropubic prostatectomy, and in 2 studies the participants received radical prostatectomy. Included studies assessed the following interventions: preoperative vs postoperative PFMT (2 studies), supervised vs home-based PFMT (3 studies), unsupervised PFMT vs no treatment at all (2 studies), and PFMT combined with resistance and flexibility exercises vsPFMT alone (1 study).

\section{The Study Groups Were Also}

\section{Characterized Using The Following Criteria} Body Mass Index (BMI)

Patient BMI was assessed in four studies. ${ }^{8,12-14}$ In all these studies, BMI results suggested that patients are overweight. Obesity is a risk factor for prostate cancer progression, and it may worsen the treatment results. However, there is little research to be found on the relationship between obesity and UI in male patients after radical prostatectomy. Wei et al. ${ }^{16}$ carried out a meta-analysis of studies on the relationship between the BMI and urinary incontinence in men after radical prostatectomy. The findings showed that obesity may be a urinary incontinence risk factor in male patients 12 and 24 months after roboticassisted laparoscopic radical prostatectomy (RLRP). Nevertheless, no significant association was observed between obesity and urinary incontinence in male patients 24 months after laparoscopic radical prostatectomy (LRP).

\section{Clinical T-Stage}

The stage of prostate cancer was determined in seven studies. $^{7,9-14}$ The American Joint Committee on Cancer TNM system ( $\mathrm{T}$ - tumor; $\mathrm{N}$ - nodes; $\mathrm{M}$ - metastasized) is a standard tool used by healthcare professionals for pathological classification of tumors, commonly used to define prostate cancer stage. The TNM most recent update was is in January $2018 .^{17}$

\section{The Gleason Score}

The aggressiveness of prostate cancer was determined in five studies. ${ }^{8,12-15}$ This grading system may be used to choose appropriate treatment options. The Gleason Score ranges from 1 to 5 , and it describes how closely a biopsy sample resembles healthy tissue (lower score) or abnormal tissue (higher score) ${ }^{18}$

\section{Prostate-Specific Antigen (PSA)}

Patient PSA was determined in seven studies. ${ }^{8,12-15}$ Prostate-specific antigen is a glycoprotein produced in the prostate gland. Elevated PSA concentration in blood is an indicator of prostatic hypertrophy or prostate cancer. The PSA antigen is considered a sensitive marker for 
detecting and treating prostate cancer. PSA concentration up to $4 \mathrm{ng} / \mathrm{mL}$ is regarded as normal. ${ }^{19}$

\section{Outcome Measures}

The following diagnostic tests were used in the research studies covered in this systematic review:

\section{Muscle Strength}

In their studies, Nilssen et al assessed muscle strength during a palpation exam. ${ }^{12}$ Whereas Overgard et al assessed pelvic floor muscle strength using anal pressures during pelvic floor muscle contractions. ${ }^{13}$ For this purpose, the authors used a balloon catheter attached to a pressure transducer.

\section{Urodynamic Examination, Pad Test, And Bladder Diary}

The 24-hr pad test was conducted in subjects from seven studies, ${ }^{8-11,13-15}$ and the 1-hr pad test was performed only in one study. ${ }^{10}$ The 3-day bladder diary was used in three studies. ${ }^{8,10,14}$ Subjects underwent urodynamic examination in two studies. ${ }^{9,10}$

\section{Health-Related Quality Of Life (HRQOL)}

The following tools were used to assess the HRQOL: University of California, Los Angeles Prostate Cancer Index $;^{12}$

Short Form- $12^{12}$ International Continence Society Male Short Form; ${ }^{8,14}$ Medical Outcomes Study 36-item Short Form $;{ }^{14}$ and the Health-Related Quality of Life Questionnaire. $^{12}$

\section{Other Questionnaires}

In their studies, Centemero et al examined patients' cognitive abilities using the Mini Mental State Examination. ${ }^{8}$ Park et al used the Beck Depression Inventory to assess the presence of depressive syndrome symptoms. ${ }^{14}$ Whereas Manaserro et al used the Visual Analogue Scale in their studies. ${ }^{11}$

\section{The Experimental Group Versus The Control Group}

In the studies of Filocamo et al. ${ }^{10}$ and Manaserro et al. ${ }^{11}$ the experimental groups received PFMT, whereas the control groups did not receive any therapeutic intervention. In both of these studies, better results were observed in the experimental group. Five studies ${ }^{8,9,12,13}$ compared physiotherapistguided PFMT (EG) with unsupervised PFMT performed after receiving verbal training instructions (CG). In all referenced studies, better results were observed in patients that underwent physiotherapist-guided PFMT.
In the studies of Patel et al. ${ }^{15}$ the experimental group started physiotherapist-guided PFMT 4 weeks prior to the surgery, and the control group received verbal training instructions on PFMT from a surgeon. All patients were offered physiotherapist-guided PFMT postoperatively. The study results demonstrated that a physiotherapist-guided PFMT started 4 weeks prior to the surgery significantly reduced urinary incontinence duration and severity. Whereas Park et al. ${ }^{14}$ compared a combined exercise intervention (resistance, flexibility, PFMT) (EG) with PFMT alone (CG). No statistically significant differences in UI severity between the groups were observed during the basic assessment.

\section{Treatment Start Point}

In two studies, ${ }^{8,15}$ the experimental groups started a physiotherapist-guided PFMT a month prior to the surgery and continued treatment after the surgery. Whereas the control group patients received verbal training instructions on PFMT. The authors of these studies suggest that preoperative PFMT may improve incontinence and quality of life outcomes after RP.

\section{Treatment Duration}

In the analyzed studies, the treatment lasted for 1-12 months. Furthermore, five studies analyzed the treatment efficacy at different time intervals. In their studies, Centemero et al. ${ }^{8}$ demonstrated that patients who underwent preoperative PFMT had a 0.41 -fold lower risk of being incontinent 1 month after RP and a 0.38 -fold lower risk of being incontinent 3 months after RP. In the studies of Patel et al. ${ }^{15}$ the primary outcome measure was a 24-hr pad weight test conducted at 6 weeks and 3 months postoperatively. Overgard et al. ${ }^{13}$ assessed treatment efficacy in two intervention groups at 6 weeks, 3, 6, and 12 months after the surgery. Both groups received training instructions on PFMT. However, one of the groups was offered additional follow-up training instructions from a physiotherapist during a year. No statistically significant differences in continence status between the groups were found at 3 months postoperatively; however, at 12 months postoperatively, better results were observed in the group that was offered additional follow-up training instructions. Filocamo et al. ${ }^{10}$ assessed results of the experimental group after PFMT and the control group that was not offered any therapeutic intervention. In the EG, $19 \%$ of patients achieved continence after 1 month, and $94.6 \%$ after 6 months. In the CG, $8 \%$ of patients achieved continence after 1 month, and $65 \%$ after 6 months. In their studies, Manassero et al. ${ }^{11}$ 


\begin{tabular}{|c|c|c|c|c|}
\hline 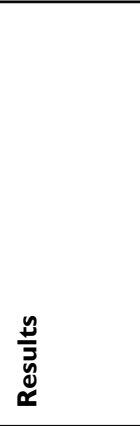 & 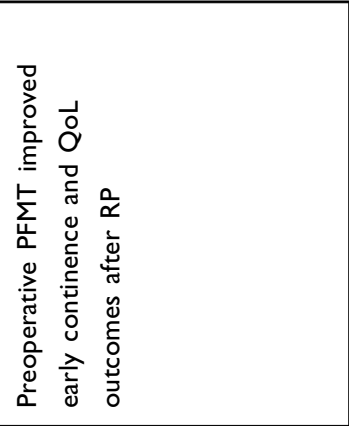 & 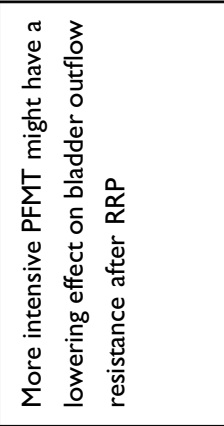 & 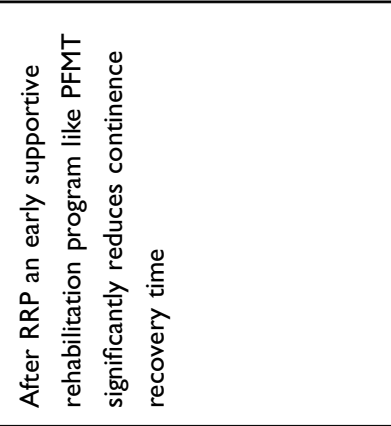 & 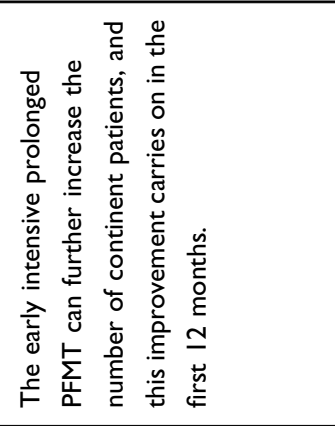 \\
\hline 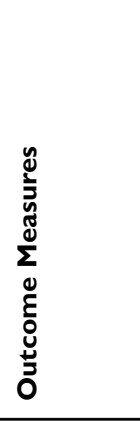 & 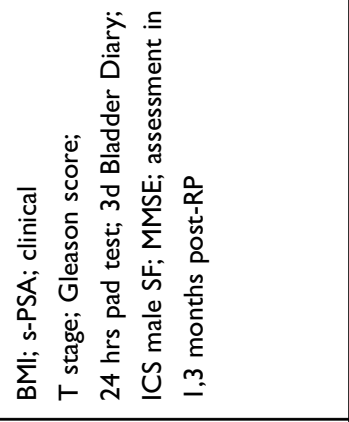 & 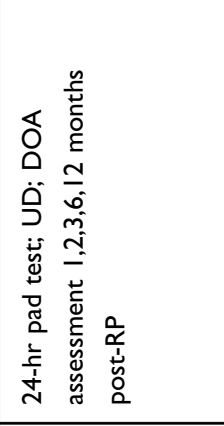 & 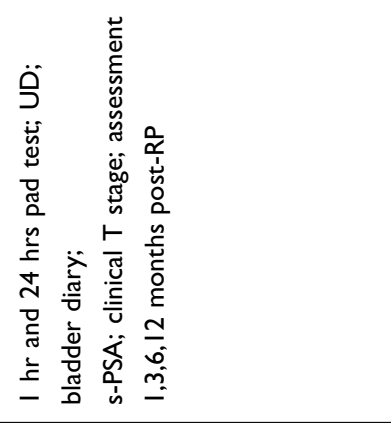 & 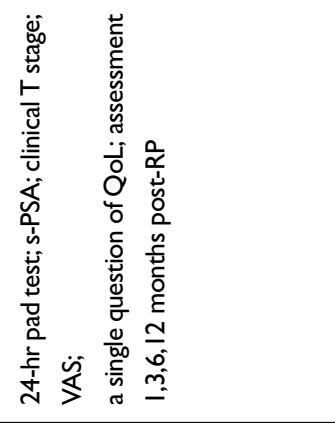 \\
\hline 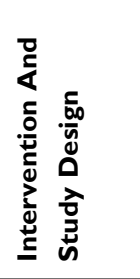 & 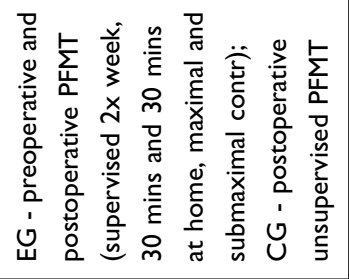 & 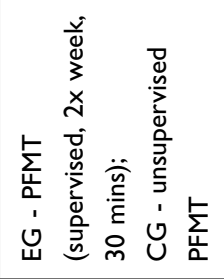 & 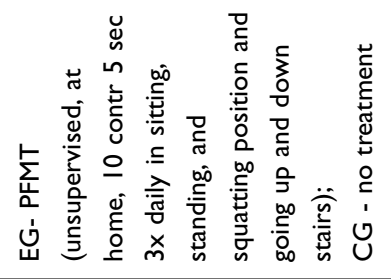 & 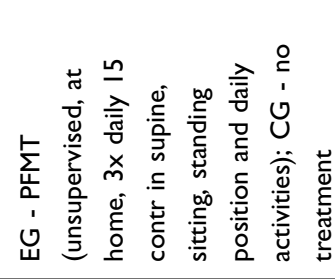 \\
\hline 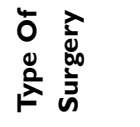 & $\hat{\alpha}$ & 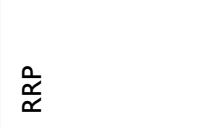 & $\begin{array}{l}\frac{\hat{\alpha}}{\alpha} \\
\frac{1}{2}\end{array}$ & $\frac{0}{\stackrel{\alpha}{\alpha}}$ \\
\hline 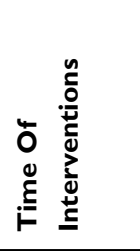 & 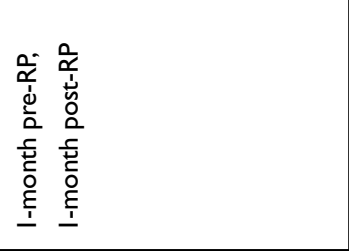 & 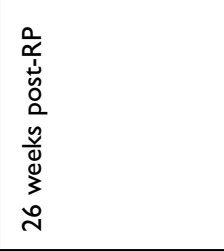 & 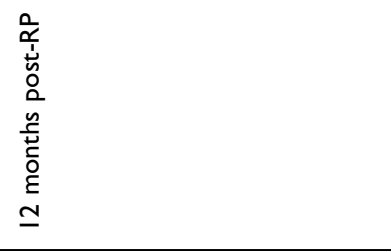 & 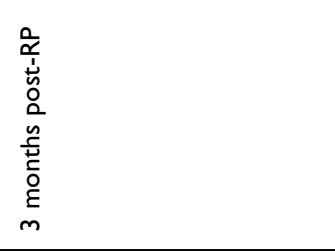 \\
\hline 造 & 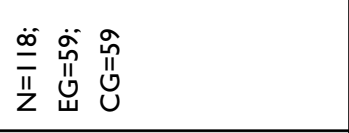 & 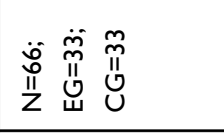 & 容兽员 & 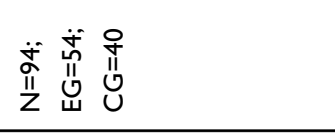 \\
\hline 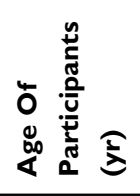 & 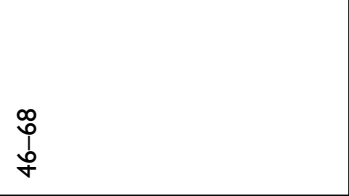 & $\begin{array}{l}0 \\
\vdots \\
0\end{array}$ & $\begin{array}{l}\stackrel{n}{\hat{\jmath}} \\
\dot{b}\end{array}$ & 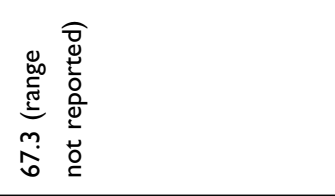 \\
\hline نे & 첲 & 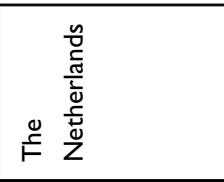 & 츨 & 초 \\
\hline 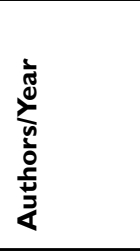 & 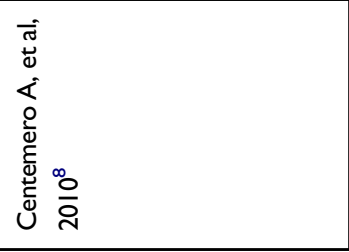 & 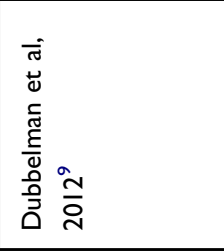 & 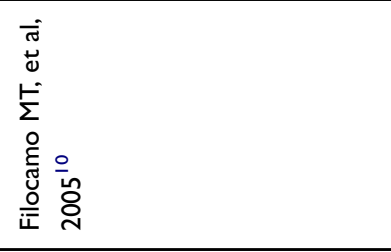 & 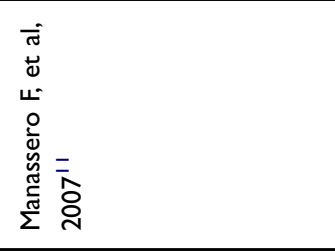 \\
\hline
\end{tabular}




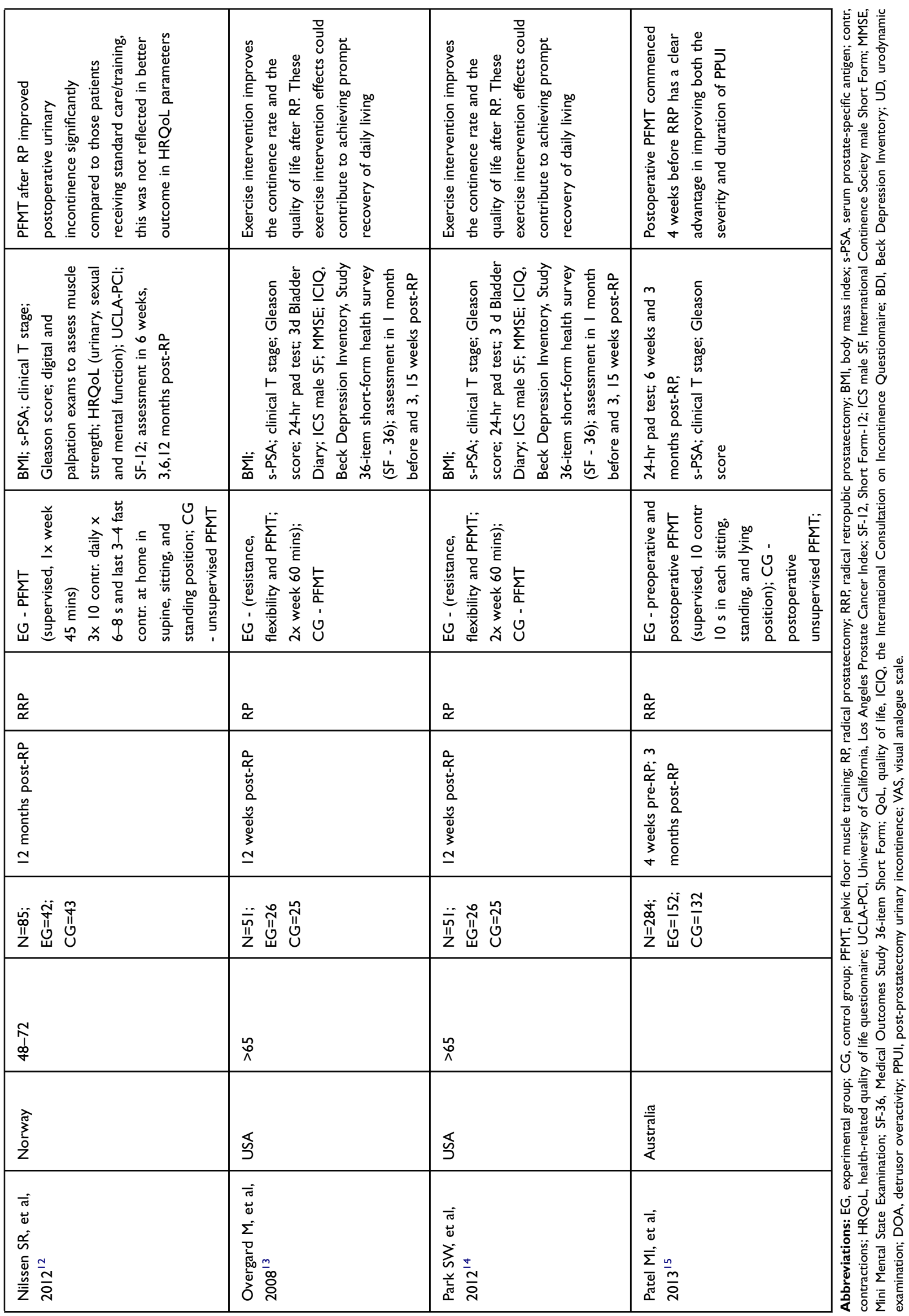


assessed the EG (PFMT treatment) and CG (no treatment) results at 1, 3, 6, and 12 months postoperatively. At each time point, better results were reported for all measured variables for the EG.

\section{Pelvic Floor Muscle Training Regimen}

The PFMT regimens vary considerably across the analyzed studies. Significant differences were observed between each PFMT regimen when it comes to contraction number and duration as well as the PFMT session frequency per day. Pelvic floor muscle training regimens are summarized in Table 2.

Filocamo et al. ${ }^{10}$ instructed the patients to perform PFMT exercises 3 times a day (10 contractions lasting $5 \mathrm{~s}$ with $10 \mathrm{~s}$ of muscular relaxation). The PFMT regimen of Manassero et al. ${ }^{11}$ comprised a series of 15 contractions repeated 3 times a day, whereas Patel et al proposed ${ }^{15} 10$ contractions lasting $10 \mathrm{~s}$. Additionally, in the two latter studies, the PFMT treatment was divided into a training of slow-twitch fibers and a training of fast-twitch fibers. Nilssen et al. ${ }^{12}$ and Overgard et al. ${ }^{13}$ instructed their patients to perform additional 3-4 fast contractions following each PFMT session (10 contractions of 6-8 s). Moreover, in most of the studies, PFMT was performed in supine, sitting, and standing positions. Dubbelman et al. ${ }^{9}$ and Park et al. ${ }^{14}$ described PFMT treatment frequency (twice a week) and session duration (30-60 mins) in the methodology sections. Whereas Centemero et al. ${ }^{8}$ also provided additional information on contraction types (maximal and submaximal) but did not include their number.

\section{Limitations}

Methodological differences and a small amount of research.

\section{Conclusion}

Findings of this review highlighted that PFMT is an effective treatment for UI in men after radical prostatectomy. PFMT improves not only physical parameters but also the quality of life of men after RP. There is a need for further research to determine the exact procedure for pelvic floor muscle exercise in men after radical prostatectomy.

\section{Acknowledgements}

This research did not receive any grant from funding agencies in the public, commercial, or non-profit sectors.

\section{Author contributions}

All authors contributed toward data analysis, drafting and critically revising the paper. The authors gave final approval of the version to be published and agree to be accountable for all aspects of the work.

\section{Disclosure}

The authors report no conflicts of interest in this work.

\section{References}

1. Pernar CH, Ebot EM, Wilson KM, Mucci LA. The epidemiology of prostate cancer. Cold Spring Harb Perspect Med. 2018;8(12):pii: a030361. doi:10.1101/cshperspect.a030361

2. Rawla P. Epidemiology of prostate cancer. World J Oncol. 2019;10 (2):63-89. doi:10.14740/wjon 1191

3. EAU Guidelines. Edn. presented at the EAU Annual Congress Barcelona. Barcelona, Spain 2019.

4. Nam RK, Cheung P, Herschorn S, et al. Incidence of complications other than urinary incontinence or erectile dysfunction after radical prostatectomy or radiotherapy for prostate cancer: a population-based cohort study. Lancet Oncol. 2014;15:223-231. doi:10.1016/S1470-2045(13)70606-5

5. Schröder A, Abrams P, Andersson KE, et al. EAU guidelines on urinary incontinence. European Association of Urology 2010. Available from: http://www.uroweb.org/guidelines/online-guidelines/. Accessed October 29, 2019.

6. Liberati A, Altman DG, Tetzlaff J, et al. The PRISMA statement for reporting systematic reviews and meta-analyses of studies that evaluate healthcare interventions: explanation and elaboration. $B M J$. 2009;339:b2700. doi:10.1136/bmj.b2700

7. De Morton NA. The PEDro scale is a valid measure of the methodological quality of clinical trials: a demographic study. Aust J Physiother. 2009;55(2):129-133. doi:10.1016/S0004-9514(09)70043-1

8. Centemero A, Rigatti L, Giraudo D, et al. Preoperative pelvic floor muscle exercise for early continence after radical prostatectomy: a randomised controlled study. Eur Urol. 2010;57:1039-1043. doi:10.1016/j.eururo.2010.02.028

9. Dubbelman Y, Groen J, Wildhagen M, Rikken B, Bosch R. Urodynamic quantification of changes in detrusor function and pressure-flow parameters after radical prostatectomy: relation to postoperative continence status and the impact of intensity of pelvic floor muscle exercises. Neurourol Urodyn. 2012;31(5):637-641. doi:10.1002/nau.v31.5

10. Filocamo MT, Li Marzi V, Del Popolo G, et al. Effectiveness of early pelvic floor rehabilitation treatment for post-prostatectomy incontinence. Eur Urol. 2005;48:734-738. doi:10.1016/j.eururo.2005.06.004

11. Manassero F, Traversi C, Ales V, et al. Contribution of early intensive prolonged pelvic floor exercises on urinary continence recovery after bladder neck-sparing radical prostatectomy: results of a prospective controlled randomized trial. Neurourol Urodyn. 2007;26(7):985-989. doi:10.1002/(ISSN)1520-6777

12. Nilssen SR, Mørkved S, Overgård M, Lydersen S, Angelsen A. Does physiotherapist-guided pelvic floor muscle training increase the quality of life in patients after radical prostatectomy? A randomized clinical study. Scand J Urol Nephrol. 2012;46(6):397-404. doi:10.3109/00365599.2012.694117

13. Overgard M, Angelsen A, Lydersen S, Morkved S. Does physiotherapist-guided pelvic floor muscle training reduce urinary incontinence after radical prostatectomy? A randomised controlled trial. Eur Urol. 2008;54:438-448. doi:10.1016/j.eururo.2008.04.021

14. Park SW, Kim TN, Nam JK, et al. Recovery of overall exercise ability, quality of life, and continence after 12-week combined exercise intervention in elderly patients who underwent radical prostatectomy: a randomized controlled study. Urology. 2012;80(2):299305. doi:10.1016/j.urology.2011.12.060 
15. Patel MI, Yao J, Hirschhorn AD, Mungovan SF. Preoperative pelvic floor physiotherapy improves continence after radical retropubic prostatectomy. Inter J Urol. 2013;20(10):986-992.

16. Wei Y, Wu YP, Lin MY, et al. Impact of obesity on long-term urinary incontinence after radical prostatectomy: a meta-analysis. Biomed Res Int. 2018;2018:8279523. Published 2018 Apr 3. doi:10.1155/2018/8279523

17. American Joint Committee on Cancer. Prostate. In: AJCC Cancer Staging Manual. 8th. New York, NY: Springer; 2017:715-725.
18. Gleason DF. The Veteran's Administration Cooperative Urologic Research Group: histologic grading and clinical staging of prostatic carcinoma. In: Tannenbaum M, editor. Urologic Pathology: The Prostate. Philadelphia: Lea and Febiger; 1977:171-198.

19. Carter HB, Albertsen PC, Barry MJ, et al. Early detection of prostate cancer: AUA guideline. J Urol. 2013;190:419-426. doi:10.1016/j. juro.2013.04.119
Clinical Interventions in Aging

\section{Publish your work in this journal}

Clinical Interventions in Aging is an international, peer-reviewed journal focusing on evidence-based reports on the value or lack thereof of treatments intended to prevent or delay the onset of maladaptive correlates of aging in human beings. This journal is indexed on PubMed Central, MedLine, CAS, Scopus and the Elsevie

Submit your manuscript here: https://www.dovepress.com/clinical-interventions-in-aging-journa
Dovepress

Bibliographic databases. The manuscript management system is completely online and includes a very quick and fair peer-review system, which is all easy to use. Visit http://www.dovepress.com/ testimonials.php to read real quotes from published authors. 